\title{
Submucosal tunneling endoscopic septum division for treatment of Zenker's diverticulum
}

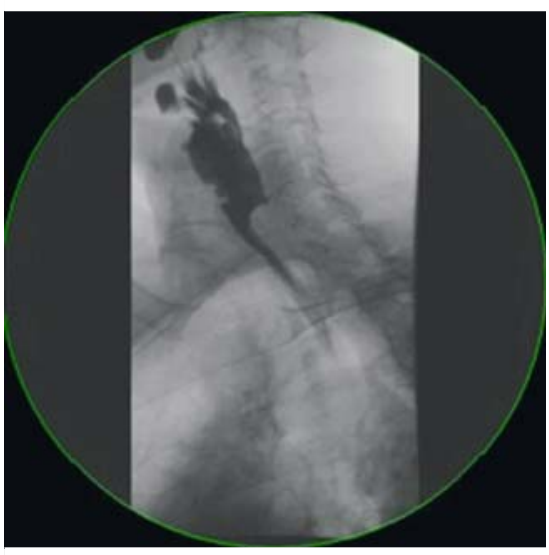

- Fig. 1 Esophagram showing close to complete resolution of the Zenker's diverticulum post procedure.

A 71-year-old man who reported 4 years of dysphagia with solid food, as well as halitosis and regurgitation of undigested food, was diagnosed with Zenker's diverticulum after a barium esophagram. After discussing all potential therapeutic options with the patient, he was offered a submucosal tunneling endoscopic septum division (STESD) technique [1]. This technique involves creating a mucosal incision to create an entry point to the submucosal space, and subsequent tunneling and dissection of the submucosal space to expose the Zenker's septum on both sides, and then performing a complete myotomy under direct vision, which leads to resolution of the diverticulum ( $\vee$ Video 1$)$. STESD was performed in the patient without immediate complications.

On postoperative Day 1 a single-contrast esophagram showed no esophageal leak and almost complete resolution of the diverticulum ( $\triangleright$ Fig. 1 ). The patient was discharged home. Outpatient follow-up after 30 days showed resolution of dysphagia and weight gain.

Zenker's diverticulum is a false diverticulum with outpouching of the esophageal

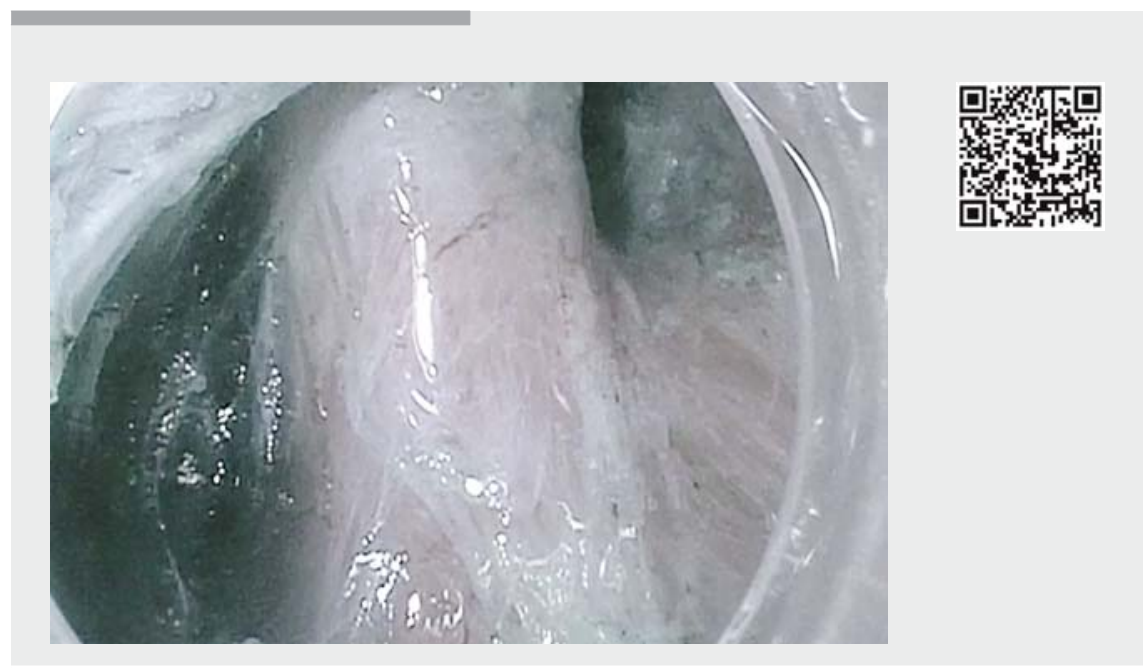

$\checkmark$ Video 1 Tunneling technique to expose the septum and perform complete dissection.

mucosa and submucosa posteriorly and proximally to the cricopharyngeal muscle [2]. The majority of affected patients are older men who typically present with dysphagia, halitosis, and regurgitation of undigested food [3]. Symptomatic Zenker's diverticulum can be treated with open surgery, or alternatively through flexible endoscopic techniques. The conventional method of endoscopic septum division involves incision of the mucosa in addition to the muscular fibers that form the diverticular septum. STESD is a novel method for the treatment of Zenker's diverticulum, and allows complete dissection of the muscle fibers under direct visualization [1]. Importantly, submucosal tunneling preserves the integrity of the mucosal layer by performing the myotomy in the submucosal space, potentially decreasing the risk of perforation and infection, and facilitating rapid healing. This case illustrates that STESD can be used safely and effectively to treat symptomatic Zenker's diverticulum.

Endoscopy_UCTN_Code_TTT_1AO_2AN
Competing interests

Dr. Kahaleh has received research and training grants from BSC, Cook, Olympus, Gore, Emcision, and Pinnacle.

\section{The authors}

Kaveh Hajifathalian', Qais Dawod', Monica Saumoy ${ }^{1}$, Michel Kahaleh ${ }^{2}$

1 Department of Gastroenterology, Weill Cornell Medicine, New York Presbyterian Hospital, New York, New York, United States

2 Department of Gastroenterology, Robert Wood Johnson Medical Center, New Brunswick, New Jersey, United States

\section{Corresponding author}

Michel Kahaleh, MD, AGAF, FACG, FASGE Department of Gastroenterology, Robert Wood Johnson University Hospital, 1 RWJ Place, MEB 464, New Brunswick, NJ 08901, United States

Fax: +1-732-2357307

mkahaleh@gmail.com 
[1] Li QL, Chen WF, Zhang XC et al. Submucosal tunneling endoscopic septum division: a novel technique for treating Zenker's diverticulum. Gastroenterology 2016; 151: $1071-1074$

[2] Siddiq MA, Sood S, Strachan D. Pharyngeal pouch (Zenker's diverticulum). Postgrad Med J 2001; 77: 506 - 511

[3] Mulder C], Costamagna G, Sakai P. Zenker's diverticulum: treatment using a flexible endoscope. Endoscopy 2001; 33: $991-997$

\section{Bibliography}

DOI https://doi.org/10.1055/a-0665-4173

Published online: 27.9.2018

Endoscopy 2018; 50: E340-E341

(c) Georg Thieme Verlag KG

Stuttgart · New York

ISSN 0013-726X

\section{ENDOSCOPY E-VIDEOS}

https://eref.thieme.de/e-videos

回的 Endoscopy E-Videos is a free access online section, reporting 自: on interesting cases and new

techniques in gastroenterological endoscopy. All papers include a high quality video and all contributions are freely accessible online.

This section has its own submission website at

https://mc.manuscriptcentral.com/e-videos 